Journal Club

Editor's Note: These short reviews of a recent paper in the Journal, written exclusively by graduate students or postdoctoral fellows, are intended to mimic the journal clubs that exist in your own departments or institutions. For more information on the format and purpose of the Journal Club, please see http://www.jneurosci.org/misc/ifa_features.shtml.

\title{
Inhibition of Fatty Acid Amide Hydrolase: A Potential Treatment for Neuropathic Pain
}

\author{
Tuan Trang \\ University of Toronto Centre for the Study of Pain, Program in Neuroscience and Mental Health, Hospital for Sick Children, Toronto, Ontario, Canada \\ M5G 1X8 \\ Review of Jhaveri et al. (http://www.jneurosci.org/cgi/content/full/26/51/13318)
}

There are limited treatment options for neuropathic pain, a debilitating condition characterized by pain hypersensitivity. There is, however, growing interest in cannabinoids because $\mathrm{CB}_{1^{-}}$and $\mathrm{CB}_{2}{ }^{-}$ receptor agonists are analgesic in acute and chronic pain, and increases in endogenous cannabinoids are effective in animal models of neuropathic pain (Bridges et al., 2001; Jayamanne et al., 2006).

A recent study in The Journal of Neuroscience by Jhaveri et al. (2006) investigated whether inhibition of fatty acid amide hydrolase (FAAH) alters responses of dorsal horn neurons in neuropathic pain (Fig. 1). FAAH is the enzyme responsible for metabolism of the endocannabinoid anandamide. Jhaveri et al. (2006) report a marked reduction in paw-withdrawal threshold, indicative of mechanical allodynia in spinal nerve-ligated (SNL), but not in sham-operated rats. Increasing weights of monofilaments applied to the hindpaw of SNL or sham-operated rats evoked an incremental increase in neuronal firing in wide dynamic-range spinal dorsal horn neurons in vivo [Jhaveri et al. (2006), their Fig. 1 (http://www.jneurosci.

Received Feb. 9, 2007; revised Feb. 21, 2007; accepted Feb. 22, 2007.

This work was supported by grants from the Canadian Institutes of Health Research and Neuroscience Canada. The author thanks Dr. Simon Beggs for assistance with figure illustrations.

Correspondence should be addressed to Tuan Trang, Program in Neuroscience and Mental Health, Hospital for Sick Children, Toronto, Ontario, Canada M5G 1X8. Email: tuan.trang@utoronto.ca.

DOI:10.1523/JNEUROSCI.0583-07.2007

Copyright $\odot 2007$ Society for Neuroscience $\quad 0270-6474 / 07 / 273364-02 \$ 15.00 / 0$
org/cgi/content/full/26/51/13318/F1)]. The firing frequency, however, was lower in the SNL group regardless of whether the stimulus intensity was innocuous or noxious consistent with a reduction in "peripheral drive" and an overall decrease in spinal neuronal excitability after peripheral nerve injury (Chapman et al., 1998).

Intraplantar injection of URB597, an FAAH inhibitor, suppressed the mechanically evoked responses of wide dynamicrange spinal neurons in sham-operated rats [Jhaveri et al. (2006), their Fig. $2 \mathrm{~A}$ (http://www.jneurosci.org/cgi/content/full/ 26/51/13318/F2)] and elevated levels of anandamide, oleoyl ethanolamide, and 2 -arachidonyl glycerol [Jhaveri et al. (2006), their Fig. 5 (http://www. jneurosci.org/cgi/content/full/26/51/ 13318/F5)]. The latter finding suggests this effect may involve peripheral endocannabinoids. In contrast, a fourfold higher dose of intraplantar URB597 was required to inhibit neuronal responses in SNL rats [Jhaveri et al. (2006), their Fig. $2 B$, (http://www.jneurosci.org/cgi/ content/full/26/51/13318/F2)], and did not coincide with an increase in peripheral endocannabinoids. Jhaveri et al. (2006) attributed this result to increased FAAH activity and to changes in $\mathrm{pH}$ in the hindpaw of neuropathic rats, which would attenuate the potency of the drug. The authors also suggest that peripheral levels of endocannabinoids in SNL rats could have been affected by alternate met- abolic pathways, such as the cyclooxygenase pathway. However, in addition to these possibilities, endocannabinoid levels could have been influenced by activity of the lipoxygenase pathway or by endocannabinoid carrier-mediate reuptake.

Spinal administration of URB597 also inhibited mechanically evoked responses of wide dynamic-range neurons and elevated endocannabinoid levels in the ipsilateral spinal cord of sham and SNL rats [Jhaveri et al. (2006), their Figs. 3 (http:// www.jneurosci.org/cgi/content/full/26/ 51/13318/F3), 6 (http://www.jneurosci. org/cgi/content/full/26/51/13318/F6)]. It would be interesting to determine whether activity of nociceptive specific dorsal horn neurons was also affected.

The actions of URB597 were blocked by pretreatment with $\mathrm{AM}-251$, a $\mathrm{CB}_{1}$ receptor antagonist, and by naloxone, an opioid-receptor antagonist [Jhaveri et al. (2006), their Figs. 2 (http://www. jneurosci.org/cgi/content/full/26/51/ 13318/F2), 3 (http://www.jneurosci.org/ cgi/content/full/26/51/13318/F3)]. Thus, the functional effects of URB597 are mediated by $\mathrm{CB}_{1}$-receptors and involve interaction with the endogenous opioid system. The mechanism underlying such interaction is not known, but $\mathrm{CB}_{1}$-receptors are colocalized with $\mu$-opioid receptors in the spinal dorsal horn, suggesting a convergence of intracellular signaling between the two systems.

In previous studies, these authors reported that activation of peripheral 


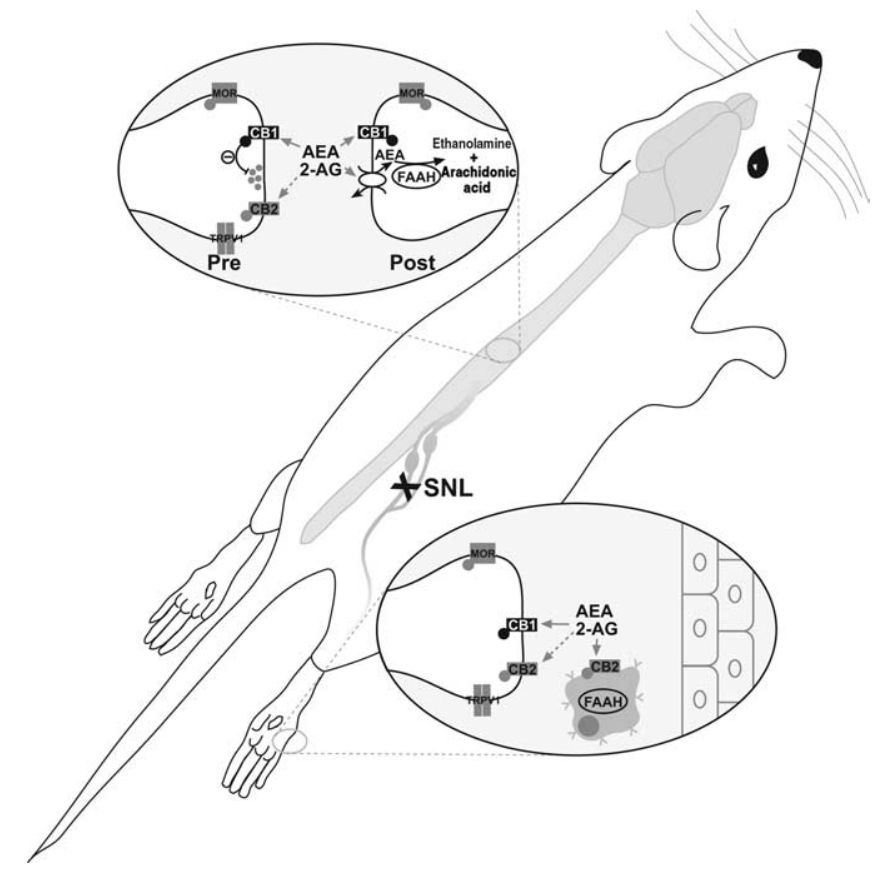

Figure 1. A schematic representation of the spinal and peripheral endocannabinoid system. The effects of anandamide (AEA) and 2-arachidonyl glycerol (2-AG) are mediated through activation of cannabinoid $\mathrm{CB}_{1}$ - and $\mathrm{CB}_{2}$-receptors. $A E A$ is internalized by a putative carrier-mediated transporter and metabolized by $\mathrm{FAAH}$ to produce arachidonic acid and ethanolamine. Although 2-AG activity is principally metabolized by monoacylglycerol lipase, termination of 2-AG activity can also occur through FAAH. Pharmacological inhibition of FAAH results in elevated endocannabinoid levels and a consequent reduction in spinal pain transmission.

$\mathrm{CB}_{2}$-receptors produces a strikingly similar reduction in mechanically evoked response of spinal neurons in SNL and sham-operated rats (Elmes et al., 2004). Others have also shown that $\mathrm{CB}_{2}$ receptors are upregulated on sensory afferent terminals in the lumbar spinal cord of nerve-injured animals (Wotherspoon et al., 2005) and agonists of $\mathrm{CB}_{2}$-receptors suppress pain hypersensitivity associated with neuropathic pain (Beltramo et al., 2006). In light of the evidence for involvement of $\mathrm{CB}_{2}$-receptors in neuropathic pain, some of the effects resulting from URB597 treatment could involve $\mathrm{CB}_{2}$-receptors.

A key issue that remains to be ad- dressed is whether inhibition of neuronal responses and augmentation of endocannabinoid levels by URB597 corresponds to a behavioral reduction in mechanical allodynia in SNL rats. This issue is important because FAAH - / - knock-out mice develop pain hypersensitivity after pe15-fold higher brain anandamide levels than wild-type controls (Lichtman et al., 2004). In addition, URB597 had no effect on mechanical allodynia in a partial sciatic nerve ligation model of neuropathic pain (Jayamanne et al., 2006), and there are concerns regarding the specificity of the drug (Zhang et al., 2007). Thus, a behavioral correlate to the neuronal effects of ripheral nerve injury, despite possessing
URB597 would strengthen the proposed link between FAAH inhibitors and the treatment of neuropathic pain.

\section{References}

Beltramo M, Bernardini N, Bertorelli R, Campanella M, Nicolussi E, Fredduzzi S, Reggiani A (2006) CB2 receptor-mediated antihyperalgesia: possible direct involvement of neural mechanisms. Eur J Neurosci 23:1530-1538.

Bridges D, Ahmad K, Rice A (2001) The synthetic cannabinoid WIN55,212-2 attenuates hyperalgesia and allodynia in a rat model of neuropathic pain. Br J Pharmcol 133:586-594.

Chapman V, Suzuki R, Dickenson AH (1998) Electrophysiological characterization of spinal neuronal response properties in anaesthetized rats after ligation of spinal nerves L5-L6. J Physiol (Lond) 507:881-894.

Elmes SJ, Jhaveri MD, Smart D, Kendall DA, Chapman V (2004) Cannabinoid CB2 receptor activation inhibits mechanically evoked responses of wide dynamic range dorsal horn neurons in naive rats and in rat models of inflammatory and neuropathic pain. Eur J Neurosci 20:2311-2320.

Jayamanne A, Greenwood R, Mitchell VA, Aslan S, Piomelli D, Vaughan CW (2006) Actions of the FAAH inhibitor URB597 in neuropathic and inflammatory chronic pain models. Br J Pharmacol 147:281-288.

Jhaveri MD, Richardson D, Kendall DA, Barrett DA, Chapman V (2006) Analgesic effects of fatty acid amide hydrolase inhibition in a rat model of neuropathic pain. J Neurosci 26:13318-13327.

Lichtman AH, Shelton CC, Advani T, Cravatt BF (2004) Mice lacking fatty acid amide hydrolase exhibit a cannabinoid receptor-mediated phenotypic hypoalgesia. Pain 109:319-327.

Wotherspoon G, Fox A, McIntyre P, Colley S, Bevan S, Winter J (2005) Peripheral nerve injury induces cannabinoid receptor 2 protein expression in rat sensory neurons. Neuroscience 135:235-245.

Zhang D, Saraf A, Kolasa T, Bhatia P, Zheng GZ, Patel M, Lannoye GS, Richardson P, Stewart A, Rogers JC, Brioni JD, Surowy CS (2007) Fatty acid amide hydrolase inhibitors display broad selectivity and inhibit multiple carboxylesterases as off-targets. Neuropharmacology 52:1095-1105. 